\title{
Herpes Simplex Virus Products in Productive and Abortive Infection
}

\author{
III. Differentiation of Infectious Virus Derived from Nucleus and \\ Cytoplasm with Respect to Stability and Size
}

SUSAN B. SPRING AND BERNARD ROIZMAN

Department of Microbiology, The University of Chicago, Chicago, Illinois 60637

Received for publication 24 June 1968

\begin{abstract}
Approximately $67 \%$ of infectivity is associated with the nucleus $8 \mathrm{hr}$ after productive infection of HEp-2 cells with herpes simplex virus. Comparison of nuclear and cytoplasmic infectious virus and macromolecular aggregates labeled with ${ }^{3} \mathrm{H}$ thymidine or with ${ }^{3} \mathrm{H}$-choline revealed the following. (i) Cytoplasmic infectious virus and macromolecular aggregates banded in $\mathrm{CsCl}$ at a density corresponding to enveloped nucleocapsids. The virus was relatively stable; there was only $50 \%$ loss of infectivity and only $16 \%$ of the virions became disaggregated. (ii) Nuclear macromolecular aggregates banded in $\mathrm{CsCl}$ solution at a density corresponding to unenveloped nucleocapsids and, moreover, both the infectious virus and aggregates were highly unstable. (iii) In sucrose density gradients, the nuclear macromolecular aggregates and infectivity sedimented as a single band and migrated more slowly than the corresponding cytoplasmic material. (iv) The infectivity of nuclear and cytoplasmic virus is readily inactivated by digestion with phospholipase $\mathrm{C}$ and with pronase. We conclude the following. (i) Cytoplasmic virus consists of enveloped nucleocapsids. (ii) Nuclear virus consists of nucleocapsids covered with lipid or partially enveloped. (iii) The molecular integrity of viral lipids is essential for infectivity. (iv) The envelope protects the nucleocapsid and accelerates adsorption to cells; it is not, however, inherently essential for infectivity.
\end{abstract}

The studies in this series concern the nature and characteristics of macromolecular aggregates of viral deoxyribonucleic acid (DNA) and protein made in productive and abortive infections of mammalian cells with herpes simplex virus. This communication deals with the properties of infectious virus extracted from the cytoplasm and nucleus of productively infected cells.

The circumstances which led to this study may be summarized briefly as follows. In the course of studies of the macromolecular aggregates of viral DNA and protein $(13,14)$, we found that $\mathrm{CsCl}$ was deleterious in that it causes disassembly of the aggregates and loss of infectivity. We also found that treatment with formaldehyde prior to exposure to $\mathrm{CsCl}$ prevents disassembly. Upon isopycnic centrifugation in $\mathrm{CsCl}$ solutions, formaldehyde-treated lysates of productively infected cells yielded three bands of viral macromolecular aggregates with buoyant densities of $1.285,1.325$, and 1.37 to $1.45 \mathrm{~g} / \mathrm{cm}^{3}$; these bands correspond to enveloped virions, naked nucleocapsids, and nucleoid particles, respectively. With the aid of formaldehyde-stabilization technique, we found that, in abortive infection of dog kidney cells with herpes simplex virus, nucleoids and very labile nucleocapsids are assembled, but the envelopment of the nucleocapsids does not take place. Electron microscopic studies of thin sections and of negatively stained preparations were in accord with the results from isopycnic centrifugation and revealed the presence of only naked nucleocapsids in the nuclei of abortively infected cells; enveloped virions were absent from the nuclei, cytoplasm, and extracellular fluid. These findings raised the question of whether the $a b$ sence of infectious progeny from dog kidney cells was due to the absence of enveloped nucleocapsids or to the defectiveness of the nonenveloped nucleocapsids made in these cells. To answer this question, it was of paramount importance to determine whether the nucleocapsids made in productively infected cells are infectious.

Previous studies on the biological activity of viral particles made in productively infected cells yielded results in general agreement with the 
thesis that the enveloped virions were infectious and that the infectivity of viral preparations was proportional to the number of enveloped virions $(12,14,16,17)$. The question that has thus far evoked divergent views is whether the naked nucleocapsids are infectious. The data published to date may be summarized as follows. (i) Watson, Wildy, and Russell (16) observed in the course of a quantitative study of the growth cycle of herpes virus in BHK-21 cells that the number of infectious units exceeded the number of enveloped nucleocapsids. They concluded that both naked and enveloped particles were infectious. The validity of their conclusion hinges exclusively on the magnitude of error inherent in particle counting and plaque assay techniques which, for lack of data, cannot be readily assessed. (ii) Smith (12) noted that on centrifugation of herpes simplex virus, infectivity was associated exclusively with the band containing enveloped virus. He concluded on that basis that the envelope was essential for infectivity. Smith's study makes the implicit assumption that centrifugation in $\mathrm{CsCl}$ solutions is not deleterious, or, at least, that $\mathrm{CsCl}$ does not selectively degrade one form of the virus in preference to the other. Both this and the preceding papers $(13,14)$ in this series show this assumption to be invalid: naked nucleocapsids are in fact more labile in $\mathrm{CsCl}$ than enveloped ones. It seems clear from the foregoing that, to determine whether nucleocapsids are infectious, the two types of particles have to be separated by a procedure which minimizes the loss of biological activity. Our attempt to resolve this question was based on electron microscopic observations (4, 5, 11; Schwartz and Roizman, in preparation) that enveloped nucleocapsids are found in the cytoplasm and between the inner and outer lamellae of the nuclear membrane, whereas naked nucleocapsids are segregated in the nucleus. The purpose of this paper is to show that infectious particles present in the nuclear extract differ from those present in the cytoplasmic extract with respect to (i) stability in $\mathrm{CsCl}$ solutions and (ii) rate sedimentation in sucrose.

\section{Materials and Methods}

Solutions. The compositions of PBS-A-G (phosphate-buffered saline supplemented with albumen and glucose), of SCS (saline citrate solution), and of 199$1 \%-\gamma$ (mixture 199 with $1 \%$ calf serum and $0.3 \%-\gamma$ globulin) have been given previously $(6-8,13)$. Trissaline consisted of $0.5 \mathrm{M} \mathrm{NaCl}, 0.2 \mathrm{M}$ tris(hydroxymethyl)aminomethane adjusted to $\mathrm{pH} 7.2$ by addition of $\mathbf{H C l}$. Sucrose was prepared as stock solutions of 5 and $55 \%(w / w)$ in distilled water. Enzyme reaction mixtures were prepared as follows. (i) Phospholipase C (PLC; Lipophosphodiesterase 1, Worthington Biochemicals Corp., Freehold, N.J.) contained:
$1.0 \mathrm{ml}$ of cell lysate, $0.1 \mathrm{ml}$ of $10 \mathrm{X}$ Tris saline, $0.1 \mathrm{ml}$ of $10 \%$ solution of bovine albumen, and $0.1 \mathrm{ml}$ of PLC solution (1.0 mg of PLC in $1.0 \mathrm{ml}$ of $3 \%$ bovine albumen). (ii) Pronase (protease, Calbiochem, Los Angeles, Calif.) contained: $1.0 \mathrm{ml}$ of cell lysate, 0.1 $\mathrm{ml}$ of 10X SCS, and $0.1 \mathrm{ml}$ of pronase solution (1.0 $\mathrm{mg}$ in $1.0 \mathrm{ml}$ of SCS).

Radiochemicals. ${ }^{3} \mathbf{H}$-thymidine-methyl (specific activity, $15 \mathrm{c} / \mathrm{mmole}$ ) was obtained from Schwarz BioResearch, Orangeburg, N.Y. ${ }^{3} \mathrm{H}$-choline-methylchloride (specific activity, $72.7 \mathrm{mc} / \mathrm{mmole}$ ) was obtained from New England Nuclear Corp., Boston, Mass. Cells were labeled in Eagle's minimal essential medium (1) containing $1 \%$ dialyzed calf serum.

Cells and virus. The pertinent properties of the HEp-2 cell line and of the MPdk strain of herpes simplex virus have been described elsewhere $(6,8,9)$. The virus was assayed in HEp-2 cells under a liquid overlay and was scored in terms of plaque-forming units (PFU) $(6,8)$.

Preparation of cell lysates. The procedure for the preparation of infected whole cell lysates has been described in detail previously (13). Briefly, monolayer cultures of $\mathrm{HEp}-2$ cells were exposed to virus for 2 $\mathrm{hr}$ at $37 \mathrm{C}$. The inoculum was then aspirated and replaced with minimal essential medium of Eagle containing $1 \%$ dialyzed calf serum and the appropriate radioisotope. After $20 \mathrm{hr}$ of incubation at $34 \mathrm{C}$, the cells were scraped, washed with PBS-A-G, and resuspended in distilled water. After swelling for $1 \mathrm{hr}$, the cells were lysed by 20 strokes with a tight-fitting Dounce homogenizer. Cell debris was removed by centrifugation at $1,500 \times g$ for $30 \mathrm{~min}$. Lysates of uninfected HEp-2 cells were prepared in the same manner.

The nuclear and cytoplasmic extracts were prepared from cells infected for $8 \mathrm{hr}$. To measure the breakage and leakage of nuclei, the cells were pulselabeled with ${ }^{3} \mathrm{H}$-thymidine immediately before Dounce homogenization. The extent of breakage and leakage after homogenization was determined from the relative amount of acid-insoluble ${ }^{3} \mathrm{H}$-thymidine in the cytoplasmic extract. In preliminary experiments, it had been noted that 4 strokes with the Dounce homogenizer selected for this study disrupted less than $2 \%$ of the nuclei of cells infected for $8 \mathrm{hr}$. At $10 \mathrm{hr}$ after infection, the cell nuclei have become so fragile that any mechanical procedure which disrupts the cell membrane also disrupts the nuclear membrane. The preparation of nuclear and cytoplasmic virus was done as follows. Monolayer cultures were exposed to virus for $2 \mathrm{hr}$ at $37 \mathrm{C}$. The cells were incubated for 6 additional $\mathrm{hr}$ at $34 \mathrm{C}$ and then scraped, washed with PBS-A-G, and resuspended in distilled water. After swelling for $15 \mathrm{~min}$ at room temperature, the cells were lysed by 4 strokes with a tight Dounce homogenizer. The nuclei and cell debris were sedimented at $1,500 \times g$ for $15 \mathrm{~min}$. The supernatant fluid was designated as the "cytoplasmic extract." The pellet was resuspended in distilled water and the nuclei disrupted by 20 strokes of the Dounce homogenizer. Cell debris was removed by centrifugation at $1,500 \times g$ for $15 \mathrm{~min}$. The supernatant fraction was designated as the "nuclear extract." 
Formaldehyde fixation. Stabilization with formaldehyde was carried out as described previously (13). Prior to stabilization, nuclear and cytoplasmic extracts were mixed with whole-cell lysates from an equal number of uninfected cells. This procedure was necessary because the reaction with formladehyde is dependent upon the ionic composition of the cell fraction. Since the nuclei and cytoplasm are known to differ with respect to ionic composition, the addition of whole-cell lysates tended to prevent preferential interaction of formaldehyde with the constituents of either fraction.

Isopycnic centrifugation of cell lysates in $\mathrm{CsCl}$ solution. The procedures were the same as those described previously (13). Briefly, centrifugations were done in SW 39 rotors for $44 \mathrm{hr}$ at $15 \mathrm{C}$ and $100,000 \times g$. At the end of the centrifugation, 5-drop fractions were collected from the bottom of the tube and were assayed for specific gravity, radioactivity, and infectivity.

Rate centrifugation in sucrose density gradients. In practice, a 1-ml amount of cell lysate was mixed with an equal volume of $5 \%$ sucrose and layered on a 14$\mathrm{ml}$ preformed linear sucrose gradient of 5 to $55 \%$ $(\mathrm{w} / \mathrm{w})$ sucrose. The gradients were centrifuged for 90 $\min$ at $24,500 \times g$ in a SW 25.3 rotor. The $1.0-\mathrm{ml}$ fractions, collected from the top of the gradient at the end of the centrifugation, were assayed for specific gravity, radioactivity, and infectivity.

Determination of acid-precipitable thymidine-labeled DNA and choline-labeled phospholipids. Samples of each fraction were precipitated with cold $7.5 \%$ trichloroacetic acid on HA Millipore filter discs (Millipore Corp., Bedford, Mass.). The fractions containing thymidine-labeled material were washed with $5 \%$ trichloroacetic acid, $75 \%$ ethyl alcohol containing $2 \%$ potassium acetate, and $75 \%$ ethyl alcohol; the discs containing choline-labeled material were washed twice with $5 \%$ trichloroacetic acid, and twice with cold distilled water. Discs were then oven-dried and immersed in a toluene-based scintillation fluid. Tritium disintegrations were counted in a Packard liquid scintillation spectrometer.

\section{Results}

Distribution of infectious virus in the cells ard the stability of infectious virus in nuclear and cytoplasmic fractions. Nuclear, cytoplasmic, and whole-cell extracts were prepared from HEp-2 cells infected for $8 \mathrm{hr}$. A sample was saved for infectivity assay (input sample). Each preparation was divided in half, mixed with an appropriate amount of $\mathrm{CsCl}$ to yield an initial density of $1.29 \mathrm{~g} / \mathrm{cm}^{3}$, and centrifuged to equilibrium. To determine the buoyant density of the infectious material, fractions were collected from one set of gradients and assayed for residual infectivity. To determine the total recovery of infectious virions, the mineral oil seal was removed from the other set of gradients and the contents of each tube were thoroughly mixed. The results of one representative experiment, summarized in Table 1,
TABLE 1. Recovery of infectivity from nuclear, cytoplasmic, and whole-cell extracts after isopycnic centrifugation in $\mathrm{CsCl}$ solutions

\begin{tabular}{|c|c|c|c|}
\hline Cell fraction & $\begin{array}{c}\text { Input } \\
\text { PFU } \\
\left(\times 10^{6}\right) \\
(\mathrm{a})\end{array}$ & $\begin{array}{c}\text { Recovered } \\
\text { PFU } \\
\left(\times 10^{6}\right) \\
\text { (b) }\end{array}$ & $\begin{array}{c}\text { Per cent } \\
\text { recovery } \\
\text { (b/a) } \\
\times 100\end{array}$ \\
\hline Nuclear. & 300 & 0.03 & 0.01 \\
\hline Cytoplasmic. & 104 & 49.0 & 47.0 \\
\hline $\begin{array}{c}\text { Sample of whole } \\
\text { cell ........... }\end{array}$ & 10 & 1.4 & 15.0 \\
\hline
\end{tabular}

show the following. (i) Prior to centrifugation, the nuclear and cytoplasmic fractions contained 67 and $33 \%$ of the total infectious intracellular virus, respectively. (ii) After centrifugation, recovery was $0.01 \%$ of the virus in the nuclear fraction, approximately $50 \%$ of the virus in the cytoplasmic fraction, and $15 \%$ of the input virus in the whole-cell lysate. (iii) Residual infectious virus in all three extracts banded at the density characteristic of enveloped virions, i.e., $1.285 \mathrm{~g} /$ $\mathrm{cm}^{3}(13,14)$.

The data indicated the following. (i) Infectious virus in the nuclear fraction differs from that in the cytoplasmic fraction with respect to stability in $\mathrm{CsCl}$ solutions. (ii) The virus recovered after centrifugation in $\mathrm{CsCl}$ has a buoyant density corresponding to that of enveloped virions (13, 14). (iii) After centrifugation, the recovery of virus from the nuclear and cytoplasmic fractions $(0.01 \%$ of $67 \%$ and $50 \%$ of $33 \%$, respectively) is in good agreement with the recovery of $15 \%$ of input virus from whole-cell extracts.

Comparison of the disaggregation of nuclear and cytoplasmic viral macromolecular aggregates on centrifugation in $\mathrm{CsCl}$ solutions. The data in the preceding section showed that the infectivity of the nuclear fraction was more readily inactivated in $\mathrm{CsCl}$ solution than that of the cytoplasmic fraction. The question arises whether the viral macromolecular aggregates in the nucleus are also more readily disaggregated by $\mathrm{CsCl}$ than are those accumulating in the cytoplasm. Previously, we have shown that viral structures can be stabilized by formaldehyde. To determine the relative stability of viral particles in $\mathrm{CsCl}$ solution, nuclear and cytoplasmic extracts of $8-\mathrm{hr}$ infected HEp-2 cells, labeled from 2 to $8 \mathrm{hr}$ after infection with ${ }^{3} \mathrm{H}$-thymidine, were divided in half. One portion was treated with formaldehyde. Both portions were mixed with an appropriate amount of $\mathrm{CsCl}$ to give a solution with an initial density of $1.29 \mathrm{~g} / \mathrm{cm}^{3}$ and then centrifuged to equilibrium. The recovery of acid-precipitable ${ }^{3} \mathrm{H}$-thymidine from the nuclear and cytoplasmic fractions is shown in Table 2. The data showed 
TABLE 2. Recovery of macromolecular aggregates containing ${ }^{3} \mathrm{H}-\mathrm{DNA}$ from nuclear and cytoplasmic extracts after isopycnic centrifugation in $\mathrm{CsCl}$ solutions

\begin{tabular}{|c|c|c|c|c|c|c|}
\hline Cell fraction & $\begin{array}{l}\text { Stabilization } \\
\text { with HCHO }\end{array}$ & $\begin{array}{c}\text { CPM recovered } \\
\text { in enveloped } \\
\text { nucleocapsid } \\
\text { band }(1.27-1.29 \\
\left.\mathrm{g} / \mathrm{cm}^{3}\right)\end{array}$ & $\begin{array}{c}\text { CPM recovered } \\
\text { in naked } \\
\text { nucleocapsid } \\
\text { band }(1.29-1.33 \\
\left.\mathrm{g} / \mathrm{cm}^{3}\right)\end{array}$ & $\begin{array}{l}\text { Total CPM } \\
\text { recovered }\end{array}$ & $\begin{array}{c}\text { Per cent } \\
\text { recovered in } \\
\text { band containing } \\
\text { enveloped } \\
\text { nucleocapsids }\end{array}$ & $\begin{array}{c}\text { Per cent } \\
\text { recovered: } \\
\text { untreated/ } \\
\text { HCHO treated }\end{array}$ \\
\hline $\begin{array}{l}\text { Nuclear...... } \\
\text { Cytoplasmic. }\end{array}$ & $\begin{array}{l}- \\
+ \\
- \\
+\end{array}$ & $\begin{array}{r}7,000 \\
26,000 \\
5,100 \\
6,100\end{array}$ & $\begin{array}{r}56,000 \\
193,000 \\
300 \\
300\end{array}$ & $\begin{array}{r}64,200 \\
219,000 \\
5,400 \\
6,400\end{array}$ & $\begin{array}{l}12.9 \\
13.5 \\
94 \\
95\end{array}$ & 29 \\
\hline
\end{tabular}

the following. (i) After isopycnic centrifugation in $\mathrm{CsCl}$ solutions, only $29 \%$ of nuclear macromolecular aggregates were recovered as compared with the recovery of $84 \%$ of aggregates accumulating in the cytoplasm. (ii) Nuclear macromolecular aggregates containing ${ }^{3} \mathrm{H}$-DNA formed a broad band encompassing the density range of naked and enveloped nucleocapsids, i.e., 1.28 to $1.33 \mathrm{~g} / \mathrm{cm}^{3}(13,14)$. (iii) Cytoplasmic macromolecular aggregates containing ${ }^{3} \mathrm{H}$-DNA band at a density characteristic of enveloped nucleocapsids, i.e., at $1.28 \mathrm{~g} / \mathrm{cm}^{3}(13,14)$.

Hydrodynamic differentiation of nuclear and cytoplasmic infectious virus in sucrose density gradients. Nuclear and cytoplasmic extracts of 8-hr infected HEp-2 cells labeled from 2 to $8 \mathrm{hr}$ after infection with ${ }^{3} \mathrm{H}$-thymidine were layered on 5 to $55 \%$ preformed sucrose gradients and centrifuged at $24,500 \times g$ for $90 \mathrm{~min}$. Fractions were collected and assayed for radioactivity, infectivity, and specific gravity of the sucrose. The results (Fig. 1) show that infectious virus present in the cytoplasmic extract sediments several fractions further in the gradient than nuclear infectious particles; the profiles of thymidine label correspond roughly to the infectivity profiles in each case. These findings were reproduced in several experiments and indicate that the infectious particles present in the nucleus are hydrodynamically smaller than those present in the cytoplasm. The recovery after centrifugation was 60 and $80 \%$ of initial infectivity of the nuclear and cytoplasmic extracts, respectively, and $100 \%$ of trichloroacetic acid-precipitable radioactivity.

Effect of phospholipase C (PLC) on the infectivity of nuclear and cytoplasmic fractions. In the preceding sections, we have shown that infectious virus extracted from nuclei of 8-hr infected cells is less stable than virus extracted from cytoplasm. The infectious cytoplasmic virus has, on the basis of its buoyant density in $\mathrm{CsCl}(8,13)$, the properties of a nucleocapsid surrounded by a lipid envelope. Previously, it has been shown that lipid solvents render herpes viruses noninfectious (9, 17). In view of the physical difference between

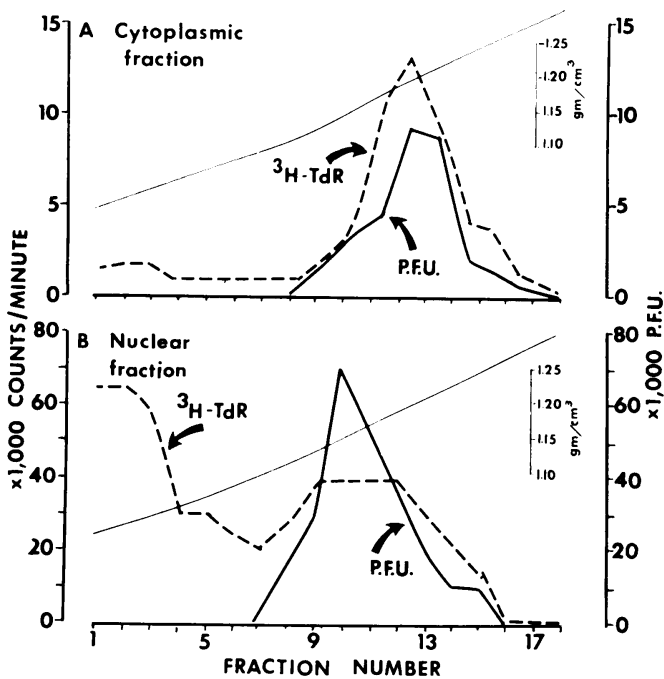

FIG. 1. Distribution of macromolecular aggregates containing ${ }^{3} \mathrm{H}$-thymidine-labeled $\mathrm{DNA}$ and infectious virus (PFU) from 8 -hr infected $\mathrm{HEp}-2$ cells on rate centrifugation in 5 to $55 \%(w / w)$ preformed sucrose gradients. (A) cytoplasmic extracts; (B) nuclear extracts. Direction of sedimentation is from left to right.

the nuclear and cytoplasmic virus indicated by the results reported in the preceding sections, the question arises whether the infectious nuclear virus also contains essential lipids. Preliminary experiments have shown that both phospholipase $\mathrm{C}$ and hog pancreas lipase inactivate herpes viruses. In these experiments, we used phospholipase $C$ because the enzyme acts by splitting off lecithin which is readily assayed. This section describes two series of experiments. In the first series, we compared the kinetics of inactivation of infectivity and the removal of labeled choline by phospholipase $\mathbf{C}$ and studied the characteristics of the inactivation reaction. In the second series, nuclear and cytoplasmic virus were compared with respect to inactivation by phospholipase $\mathbf{C}$ and by pronase. 
In the first series of experiments, two HEp-2 cultures, each containing $2 \times 10^{7}$ cells, were labeled between 2 and $18 \mathrm{hr}$ after infection with ${ }^{3} \mathrm{H}$-choline $(2.5 \mu \mathrm{c} / \mathrm{ml}$ of medium $)$ and ${ }^{3} \mathrm{H}$-thymidine $(2.5 \mu \mathrm{c} / \mathrm{ml}$ of medium $)$, respectively. Samples of lysates prepared $18 \mathrm{hr}$ after infection were incubated at $37 \mathrm{C}$ with enzyme reaction mixture and with reaction mixture (buffer) lacking enzyme. Samples for assay of residual infectivity and of acid-precipitable choline and thymidine were removed from the reaction mixtures at times indicated in Fig. 2. Digestion with enzyme resulted in a $90 \%$ loss of infectivity. Concurrently, $90 \%$ of the choline label was rendered trichloroacetic acid-soluble. The loss of infectivity and choline label followed the same kinetics, suggesting that inactivation is a consequence of choline removal and that it is not due to impurities which might be present in the enzyme preparation. The persistence of $10 \%$ of the infectivity and choline label was not the result of inactivation of the enzyme or inhibition of the reaction by end products. The enzyme-resistant fraction persisted in experiments in which additional enzyme was added after $30 \mathrm{~min}$ (to replace inactivated enzyme) or in which the entire reaction was carried out in a dialysis bag submerged in Tris-saline buffer (to remove low molecular weight endproduct inhibitors).

To determine whether phospholipase $\mathrm{C}$ removed the envelope of the virion, digested and untreated lysates were stabilized with formaldehyde and centrifuged to equilibrium in $\mathrm{CsCl}$ solutions. Both enzyme-digested and untreated virions banded at the buoyant density of enveloped

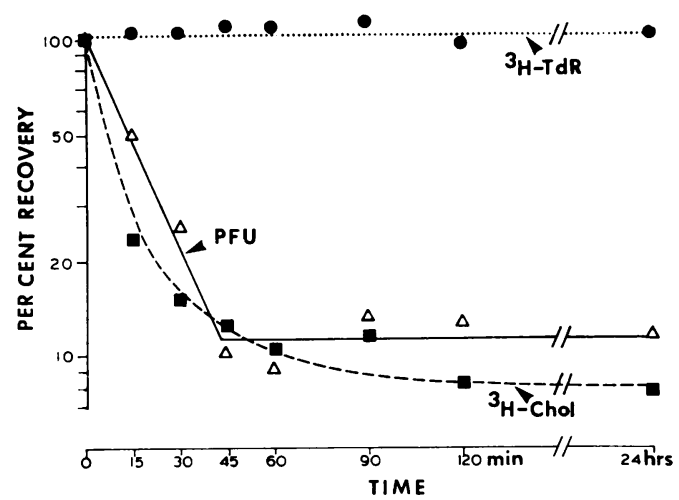

FIG. 2. Effect of phospholipase $C$ (PLC) on infectivity $(P F U)$ and trichloroacetic acid-insoluble ${ }^{3} \mathrm{H}$ choline $\left({ }^{3} \mathrm{H}\right.$-chol) and ${ }^{3} \mathrm{H}$-thymidine-methyl $\left({ }^{3} \mathrm{H}\right.$-TdR) in lysates of cells infected with herpes simplex virus. The residual activity was determined by the ratio: activity sample $\times 100 /$ initial activity. Samples were withdrawn at the times indicated. virions $\left(1.285 \mathrm{~g} / \mathrm{cm}^{3}\right)$, indicating that the enzyme did not remove substantial amounts of the envelope.

In the second series of experiments, nuclear and cytoplasmic extracts prepared from HEp-2 cells $8 \mathrm{hr}$ after infection were mixed with an excess of lysates from uninfected HEp-2 cells. This procedure was necessary to insure that the protein content and ionic composition of both extracts were equalized. The extracts were divided into three portions: one portion was incubated with phospholipase $\mathrm{C}$, one portion with pronase, and one portion with buffer. Samples for assay of residual infectivity were taken during the first $90 \mathrm{~min}$, i.e., during the period of exponential inactivation of virus shown in Fig. 2. The results (Fig. 3) show that infectious virus present in the nuclear and cytoplasmic extracts were equally sensitive to inactivation by pronase or by phospholipase $C$. The infectivity of preparations incubated with buffer remained constant throughout the time the interval studied.

\section{Discussion}

Definitions. The terms "naked" and "enveloped" herpes virus nucleocapsids define the dimensions and spacial arrangements of components to form a particular structure revealed in thin sections and in preparations stained with phosphotungstic acid; they do not specify the chemical composition of the components or the biological activity of the structure (3). In attempts to relate function or composition with a structure, numerical correlations alone are inadequate. Moreover, it has been noted by us and others (15) that electron microscopic grids loaded by techniques designed to yield the most representative sample of the preparation are not necessarily the ones

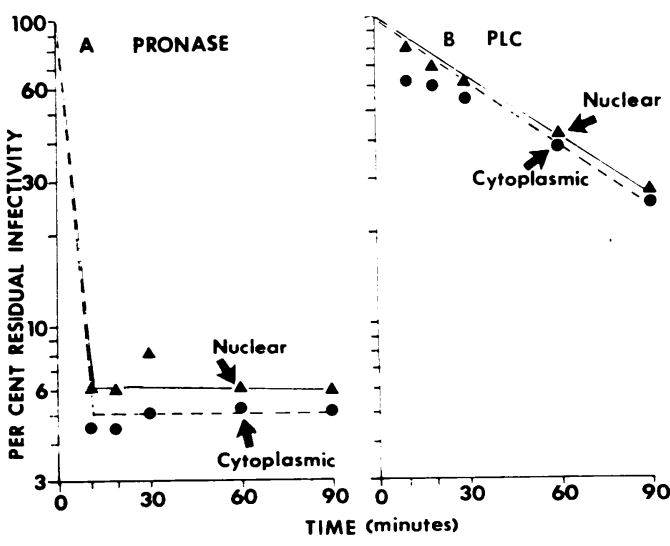

FIG. 3. Inactivation of infectivity in nuclear and cytoplasmic extracts by $(A)$ pronase; $(B)$ phospholipase $C(P L C)$. 
best suited for differentiation among naked nucleocapsids, enveloped nucleocapsids, and cell debris. We have therefore sought to correlate biological function with structure on the basis of physical characteristics of known structures established in this and in preceding papers in this series $(13,14)$.

Nature of the cytoplasmic and nuclear infectious virus. In $\mathrm{CsCl}$ solutions, cytoplasmic virus had the buoyant density characteristic of enveloped nucleocapsids $(13,14)$. Cytoplasmic virus was relatively stable in $\mathrm{CsCl}$ solutions; after centrifugation, there was only $50 \%$ loss of infectivity (Table 1) and only $16 \%$ of the virions became disaggregated (Table 2).

Labeled macromolecular aggregates in the nuclear extract formed a band in $\mathrm{CsCl}$ which encompassed the density range of both enveloped and nonenveloped nucleocapsids. From the distribution of the labeled macromolecular aggregates, we estimated (Table 2) that only $13 \%$ banded at a density characteristic of fully enveloped nucleocapsids. It seems probable, however, that this fraction consists largely of spillover from the adjacent band containing naked nucleocapsids. This conclusion is reinforced by two findings. First, the infectivity of the nuclear extracts was repeatedly reduced by centrifugation in $\mathrm{CsCl}$ solution to $0.01 \%$, as compared to $50 \%$ inactivation of the infectivity of the cytoplasmic fraction. On the basis of the $50 \%$ loss of infectivity for enveloped nucleocapsids in the cytoplasmic fraction, we may estimate that no more than $0.02 \%$ of the infectious virus in the nuclear extract is fully enveloped nucleocapsids. Second, as shown in Table 2, the material banding in the density region characteristic of enveloped nucleocapsids was as labile as the material banding in the region characteristic of unenveloped nucleocapsids.

In sucrose solutions, infectious nuclear virus behaved consistently as if it were smaller than the enveloped particles present in the cytoplasm. Two findings, i.e., the recovery of more than $60 \%$ of the infectivity after centrifugation and the coincidence of labeled macromolecular aggregates and infectivity in the sucrose solution (Fig. 1), led us to conclude that the bulk of infectious nuclear virus was devoid of intact envelope and at most was only partially enveloped. This conclusion is supported by the observation that most of the ${ }^{3} \mathrm{H}$-thymidine-labeled macromolecular aggregates in the nuclear fractions band in $\mathrm{CsCl}$ at a buoyant density characteristic of naked nucleocapsids (Table 2).

Lipids and biological activity. The experiments with phospholipase $\mathbf{C}$ clearly show that infectious nuclear virus, albeit different from enveloped nucleocapsids, contains lipids and that the molecular integrity of the lipids is essential for infectivity. In considering the relationship of the lipid to viral DNA-protein macromolecular aggregates, the following points may be made.

It seems probable that, in enveloped nucleocapsids, the lipids essential for infectivity are structural components of the envelope. We may view the envelope of the virus as having two functions. First, the envelope has a protective function. As shown in this and preceding papers $(13,14)$, enveloped virus is more stable than nonenveloped virus in $\mathrm{CsCl}$ solution. The protective function may be related to its imperviousness; enveloped virus, for example, was not readily permeable to phosphotungstic acid (14). The second function may concern adsorption to cells. Thus, Holmes and Watson (2) and Siegert and Falke (11) have demonstrated that enveloped nucleocapsids adsorb to cells more readily than nonenveloped nucleocapsids. It should be noted, however, that virus lacking an intact envelope, although unstable, is not inherently noninfectious. In addition to the data presented in this study, it has been shown by Rouhandeh et al. (10) that virus treated with lipid solvents and presumably devoid of intact envelope could be rendered infectious by adding a suspension of watersoluble inorganic compounds which absorbed the virus and adhered to cells. The physical-chemical relation of nuclear virus and lipids which render it infectious is unknown. Two possibilities should be noted. First, the lipids could be structural components of a membrane which partially envelops the virus. A partially enveloped nucleocapsid is compatible with the properties of infectious nuclear virus described in this paper. The second possibility stems from the mechanism of envelopment of the virus. The nucleocapsid is enveloped by the inner lamella of the nuclear membrane (4, 5, 11; Schwartz and Roizman, in preparation). To become enveloped, the nucleocapsid must first adhere to the membrane. The adhesion may be mediated by lipoprotein components of the nucleocapsid. In this connection, it is of interest to note that in thin sections of herpes virus virions, an electron-transparent shell separates the nucleocapsid from the electronopaque envelope (14). That the electron-transparent shell is not a part of the envelope may be deduced from negatively stained preparations. Once the envelope is fractured (15), phosphotungstic acid readily fills the space equivalent to the translucent shell and renders visible the structure of both the envelope and the nucleocapsid (14). The structure and composition of the translucent shell are unknown; it could well be that it contains lipids. 


\section{ACKNOWLEDGMENTS}

These studies were aided by American Cancer Society grants E 314D and PRA-36, Public Health Service grant CA 0849403 from the National Cancer Institute, and by National Science Foundation grant GB 4555. One of us (S. B. Spring) is a National Science Foundation predoctoral fellow.

\section{Literature Cited}

1. Eagle, H. 1959. Amino acid metabolism in mammalian cell cultures. Science 130:432-437.

2. Holmes, I. H., and D. H. Watson. 1963. An electron microscope study of the attachment and penetration of herpes virus in BHK 21 cells. Virology 21:112-123.

3. Lwoff, A., R. Horne, and P. Tournier. 1962. A system of viruses. Cold Spring Harbor Symp. Quant. Biol. 27:50-55.

4. Morgan, C., H. M. Rose, M. Holden, and E. P. Jones. 1959. Electron microscope observations of the development of herpes simplex virus. J. Exptl. Med. 110:643-656.

5. Reissig, M., and J. Melnick. 1955. The cellular changes produced in tissue cultures by herpes B correlated with the concurrent multiplication of the vrius. J. Exptl. Med. 101:341-351.

6. Roizman, B., and L. Aurelian. 1965. Abortive infection of canine cells by herpes simplex virus. I. Characterization of viral progeny from cooperative infection with mutants differing in capacity to multiply in canine cells. J. Mol. Biol. 11:528-538.

7. Roizman, B., L. Aurelian, and P. R. Roane, Jr. 1963. The multiplication of herpes simplex virus. I. The programming of viral DNA duplication in HEp-2 cells. Virology 21:482-498.

8. Roizman, B., and P. R. Roane, Jr. 1961. A physical difference between two strains of herpes simplex virus apparent on sedimentation in cesium chloride. Virology 15:75-79.

9. Roizman, B., and P. R. Roane, Jr. 1963. Demonstration of a surface difference between virions of two strains of herpes simplex virus. Virology 19:198-204.

10. Rouhandeh, H., M. L. Brinkman, and L. L. Sells. 1967. Reactivation of ether-inactivated infectious bovine rhinotracheitis virus. J. Infect. Diseases 117:237-241.

11. Siegert, R., and D. Falke. 1966. Elecktronen Mikroskopishe Untersuchungen uber die Entwicklung des Herpes Virus Hominis in Kulturezellen. Archiv Ges. Virusforsch. 19:230-246.

12. Smith, K. O. 1964. Relationship between the envelope and the infectivity of herpes simplex virus. Proc. Soc. Exptl. Biol. Med. 115:814-816.

13. Spring, S. B., and B. Roizman. 1967. Herpes simplex virus products in productive and abortive infection. I. Stabilization with formaldehyde and preliminary analyses by isopycnic centrifugation in $\mathrm{CsCl}$. J. Virol. 1:294-301.

14. Spring, S. B., B. Roizman, and J. Schwartz. 1968. Herpes simplex virus products in productive and abortive infection. II. Electron microscopic and immunologic evidence for the failure of envelopment as a cause of abortive infection. J. Virol. 2:384-392.

15. Watson, D. H. 1968. The structure of the virion in relation to its biologic functions. Symp. Gen. Soc. Microbiol, in press.

16. Watson, D. H., P. Wildy, and W. C. Russell. 1964. Quantitative electron microscopic studies on the growth of herpes virus using the techniques of negative staining and ultramicrotomy. Virology 24:204-222.

17. Wildy, P., W. C. Russell, and R. W. Horne. 1960. The morphology of herpes virus. Virology 12:204-222. 